\title{
Investigation on the Efficacy of Salmonella Bivalent Vaccine
}

\author{
Lipi Rani Basak ${ }^{1}$ and Md. Mansurul Amin ${ }^{2}$ \\ ${ }^{1,2}$ Department of Microbiology and Hygiene, Faculty of veterinary science, Bangladesh Agricultural University \\ (BAU), Bangladesh
}

\begin{abstract}
The work was performed to investigate the efficacy of Salmonella bivalent vaccine containing Salmonella gallinarum and Salmonella pullorum prepared at the Livestock and Poultry Vaccine Research and Production Centre (LPVRPC) of the Bangladesh Agricultural University (BAU). Purity and safety test of the vaccine was carried out as per OIE (2008). For efficacy test, vaccination was performed in Shaver brown chicken of group A containing 10 birds while group B comprising of 10 birds was maintained as unvaccinated control. Birds were inoculated primarily via intramuscular route at 7 weeks of age with $0.5 \mathrm{ml}\left(4.7 \times 10^{7} \mathrm{CFU} /\right.$ $\mathrm{ml}$ ) of vaccine followed by a booster dose at 35 days of primary vaccination (DPV). At 21 DPV ( 3 weeks), mean PHA antibody titre of sera samples were recorded as $104.00 \pm 11.71$ with S. gallinarum and $112.00 \pm 10.47$ with S. pullorum antigen whereas sera samples obtained at 35 DPV (5weeks) showed mean PHA antibody titre of $96.00 \pm 12.09$ and $80.00 \pm 10.47$ respectively. At 2 weeks of booster vaccination such mean PHA antibody titres were $144.00 \pm 16.00$ and $136.00 \pm 24.00 . L D_{50}$ were determined to calculate the challenge dose. Prior to challenge given at 4 weeks of booster vaccination the mean PHA antibody titres were found to be $104.00 \pm 11.71$ with both the experimental antigens while unvaccinated control group B had $\leq 4.0 \pm 0.00$. It was observed that the birds vaccinated with the schedule of bivalent vaccination and exhibiting mean titres of $104.00 \pm 11.71$ with either $S$. gallinarum or S. pullorum antigens withstood the challenge infection given IM with $1 \mathrm{ml}$ containing $8.6 \times 10^{13}$ $\mathrm{CFU} / \mathrm{ml}$ and $8.9 \times 10^{13} \mathrm{CFU} / \mathrm{ml}$ of virulent experimental bacterial cultures respectively. The PHA titre of group A birds analyzed by student $t$-test to determine the protective capacity of vaccinated chickens against challenge exposure. It was demonstrated that experimental Salmonella bivalent vaccine conferred protection against challenge infection and was found to be safe.
\end{abstract}

Keywords: Salmonella gallinarum, Salmonella pullorum, vaccine, immunogenicity, PHA titres.

\section{Introduction}

Salmonellosis is one of the most important bacterial diseases in poultry industry causing heavy economic loss through mortality and reduced productivity (Begum et. al. 1992, Haque et. al. 1997). The disease is most significant because the causal agents of the disease are transmitted vertically from parents to offsprings. The importance of Salmonellosis in poultry sector has drawn increased day by day attend on throughout the world. It is potentially responsible for various pathogenic processes in man and animals including poultry (Freeman, 1985).

There are mainly two types of Salmonella spp. namely S. gallinarum and $S$. pullorum that cause fowl typhoid and pullorum disease respectively. These two species of Salmonella are very important in poultry health because they are responsible for massive destruction. Salmonellae may cause varieties of clinical signs from acute systemic disease and gastrointestinal symptoms in the poultry flocks to embryonic problem in hatchery (Gast, 1997). Pullorum disease also known as bacillary white diarrhoea (BWD) caused by S. pullorum is usually confined to the first 2-3 weeks of age and occasionally occurs in adults (Shivaprashad, 1997). Fowl typhoid (FT) caused by S. gallinarum is frequently referred to as a disease of adult birds but there are also reports of high mortality in young indistinguishable from those associated with pullorum diseases (Threlfall and Frost, 1990). With great expansion of the poultry rearing and farming, pullorum disease and fowl typhoid have become widespread problem in Bangladesh like other countries of the world (Rahman et al., 1979) causing heavy economic losses in broiler, layer and breeding flocks. Such a loss occurs in both broiler and layer flocks due to morbidity, mortality, reduced production and chick quality. Mortality may vary from negligible to $10 \%$ and upto $80 \%$ or higher in severe outbreaks (Kumar and Kaushi, 1988, Kaura et al.1990, Kleven and Yoder, 1998). The major emphasis for preventing infections is to avoid the introduction of pathogens into the farms by increased bio-security (Gifford et al., 1987) along with vaccination. Vaccine available is both live (usually based on the Houghton 9R strain) and bacterins (killed / inactivated vaccine).

Salmonella vaccines of both live and killed type are imported and marketed in Bangladesh by different commercial companies beside those of local manufacture. It is necessary to monitor sterility, purity, safety and protective efficacy of any biologics or vaccines by respective controlling agency or an accredited agency prior to introduce it within the country for field use. Poultry Biologics Unit (PBU) recently renamed as "Livestock and Poultry Vaccine Research and Production Centre (LPVRPC) incorporated with its parent organization the 
Department of Microbiology and Hygiene, Bangladesh Agricultural University (BAU) Mymensingh produces a bivalent vaccine employing S. pullorum and S. gallinarum which are distributed for field use. The present work was undertaken with the objectives of determine the efficacy along with determination of PHA titre of sera obtained from the vaccinated birds. Hence, a thorough investigation on protective efficacy of experimentally prepared salmonella bivalent vaccine was performed in Shaver brown chicken

\subsection{Experimental layout}

\section{Materials And Methods}

The study included vaccination of Salmonella bivalent vaccine followed by measurement of antibody titre by the passive haemagglutination (PHA) test, determination of lethal dose fifty $\left(\mathrm{LD}_{50}\right)$ of the bacteria and performance of challenge test in the vaccinated and control birds (figure 1).

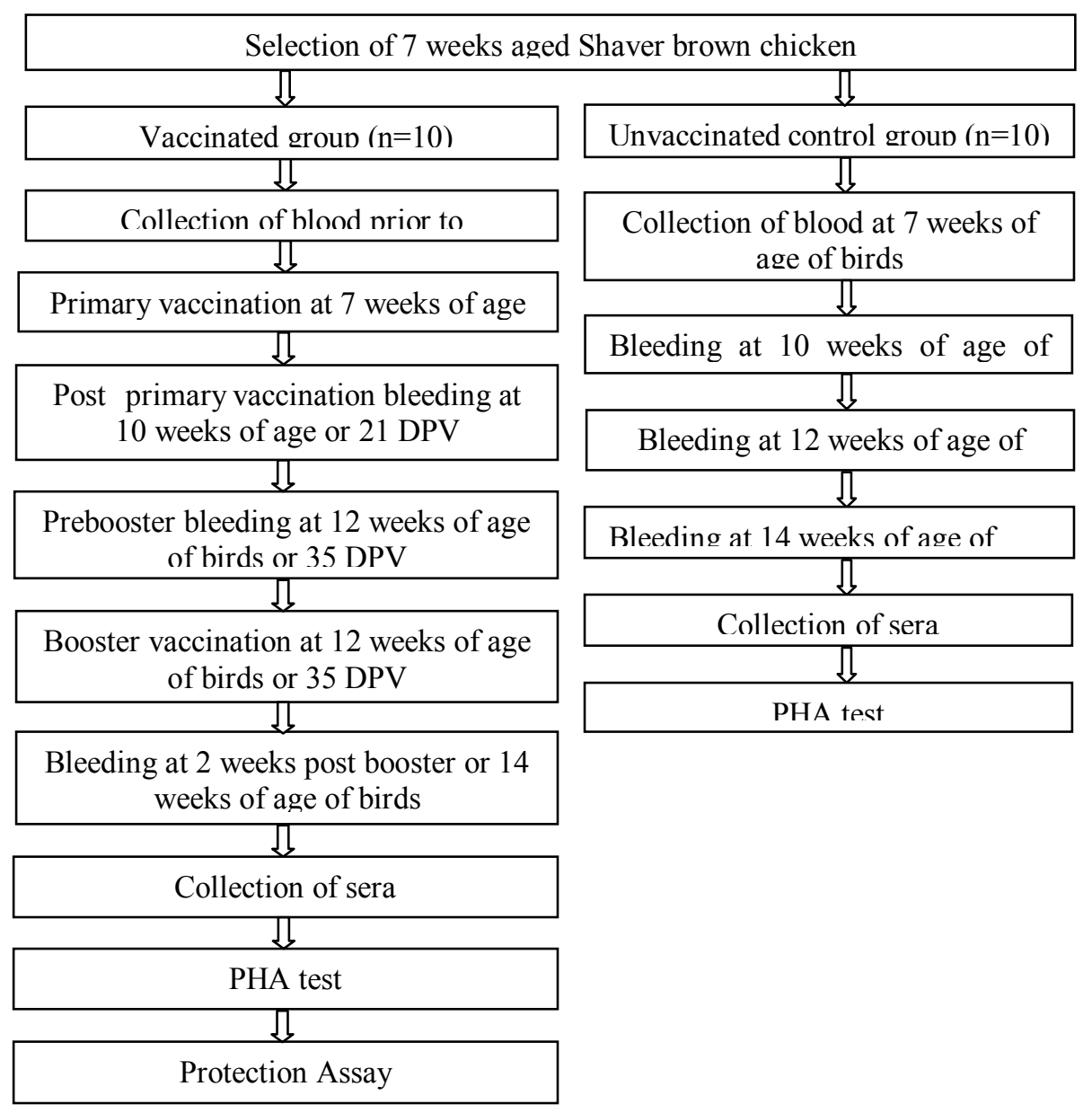

Fig- 1: Experimental layout

\subsection{Passive haemagglutination (PHA) test}

The test was used to determine the antibody titres in birds against Salmonella spp. following of vaccination as described by Carter (1979), Tripathy et al., (1970), Chowdhury et al., (1985), Sarker et al. (1976) and Siddque (1997) with slight modification.

\subsection{Principle of the test}

The sensitivity and specificity of PHA test depends on the use of soluble antigens. In this case, somatic antigens of Salmonella spp. were coupled with chemically modified horse erythrocytes so that antigen-coated erythrocytes readily react with specific antibodies and results in haemagglutination.

\subsection{Collection and preparation of $\mathbf{2 . 5 \%}$ horse red blood cells (HRBC)}

Blood was collected from the right jugular vein of a normal adult horse with sterile syringe and needle containing $5 \mathrm{ml}$ of Alsever's solution per $10 \mathrm{ml}$ of blood. The blood was centrifuged in graduated centrifuge tube at $1500 \mathrm{rpm}$ for 10 minutes. The supernatant was then pipetted off and the blood cells were resuspended with PBS and then centrifuged. The process was repeated for at least three times for washing the blood cells. During 
last washing the cells were maintained in PBS for 15 minutes and then centrifuged at $2000 \mathrm{rpm}$ for 10 minutes to obtain the packed cells. The sediment blood cells were diluted with PBS to make $2.5 \%$ suspension of the blood cells and preserved at 4 to $8^{\circ} \mathrm{C}$.

\subsection{Tannic acid solution $(1: 200)$}

Tannic acid solution (1:200) was prepared by dissolving $1 \mathrm{gm}$ of tannic acid powder in $200 \mathrm{ml}$ of distilled water in a conical flask and the solution was sterilized by autoclaving at $121^{\circ} \mathrm{C}$ maintaining a pressure of $15 \mathrm{lb}$ pressure per sq. inch for 15 minutes $\left(1 \mathrm{~kg} / \mathrm{Cm}^{2}\right)$ and kept at $4{ }^{\circ} \mathrm{C}$ to $8^{\circ} \mathrm{C}$ until used. Finally, tannic solution was prepared by mixing one $\mathrm{ml}(1: 20,000)$ of the stock solution $(1: 200)$ with $99 \mathrm{ml}$ of PBS taken in a conical flask and mixed thoroughly (Siddique, 1997)

\subsection{Inactivation and preparation of $1 \%$ normal rabbit serum diluents (NRSD)}

Collected rabbit serum was inactivated at $56^{\circ} \mathrm{C}$ in hot water bath for 30 minutes and then one $\mathrm{ml}$ of the inactivated serum was added with $99 \mathrm{ml}$ of PBS (pH 7.2) in a conical flask to obtain $1 \%$ solution. The serum solution then kept at 4 to $8^{\circ} \mathrm{C}$.

\subsection{Tannic acid treatment of horse red blood cells}

Five milliliters of $2.5 \% \mathrm{HRBC}$ and $5 \mathrm{ml}$ of 1: 20,000 dilution of tannic acid was taken in a test tube and mixed thoroughly. The mixture was then incubated at $37^{\circ} \mathrm{C}$ for 10 to 15 minutes in water bath according to the methods of Tripathy et al., (1970). The cells were centrifuged at $2000 \mathrm{rpm}$ for 10 minutes; the sediment was then washed with PBS. Washed tanned HRBC was again diluted to make $2.5 \%$ suspension with PBS and used for the test.

\subsection{Preparation of somatic antigen}

The isolates of S. gallinarum and S. pullorum organism were cultured on SS agar media. Incubated overnight at $37^{\circ} \mathrm{C}$ and selected a smooth colony and carried out slide agglutination test to ensure that the required somatic antigen is present. A pure culture on nutrient agar slope after incubation for $8-12$ hours at $37^{\circ} \mathrm{C}$ was washed off the plate by using Pasteur pipette with $2 \mathrm{ml}$ of absolute alcohol. It was then transferred into a sterile container. The antigen was left for 4-6 hours at room temperature to enable the alcohol to kill the bacteria. The container was spined for 5 minutes at $1000 \mathrm{rpm}$. The liquid was poured off and added enough phenol saline to make the antigen up to opacity. Standard titration was carried out with known serum to ensure that the antigen is positive for the required factor and stored at $4^{\circ} \mathrm{C}$.

\subsection{Sensitization of somatic antigen with tannic acid treated horse red blood cell}

Three $\mathrm{ml}$ of sensitized HRBC (2.5\%), $1 \mathrm{ml}$ of somatic antigen (1:10 dilution) and $8 \mathrm{~m} 1$ PBS were mixed together. This mixture was incubated at $37^{\circ} \mathrm{C}$ for 20 to 30 minutes. After sensitization, the cells were centrifuged at $1500 \mathrm{rpm}$ for 10 minutes, then the supernatant fluid was discarded and the sedimented HRBC was collected and diluted with $1 \%$ normal rabbit serum diluents (NRSD) at the ratio of 1: 4 . This was then mixed thoroughly and kept at room temperature for an hour and centrifuged for 10 minutes. The cells were resuspended in $1 \%$ NRSD to make $0.5 \%$ sensitized cells for use in microtitre plate method and stored at $4{ }^{\circ} \mathrm{C}$ until used (Tripathy et al., 1970).

\subsection{Microtitre plate method}

The procedure of the PHA test was followed according to the method described by Tripathy et al., (1970).

i. An amount of $50 \mu \mathrm{l}$ of PBS was first poured in each well up to 8th well of horizontal row of microtitre plate. $50 \mu \mathrm{l}$ of test serum was added in the 1 st well.

ii. Two fold dilutions of serum ranging from 1:2 to 1: 256 were made by transferring $50 \mu 1$ of the mixture from the 1st well to 2 nd well and thus continuing successively up to the $8^{\text {th }}$ well from where an excess amount of $50 \mu 1$ of the mixture was poured off.

iii. A volume of $50 \mu 10.5 \%$ somatic antigen sensitized hRBC was taken in each of the eight wells.

a. Control system, horizontal row of microtitre plate

- $9^{\text {th }}$ well: equal volume of $50 \mu \mathrm{l}$ of normal serum and PBS.

- $10^{\text {th }}$ well: equal volume of $50 \mu \mathrm{l}$ of sensitized tanned RBC and PBS.

iv. The content of the wells of the test system and control were mixed by gentle agitation of the microtitre plate and kept at room temperature for 4 to 5 hours.

v. Agglutination resulting from mixing of test serum and somatic antigen sensitized HRBC in the test system was observed very carefully.

vi. Deposition of diffuse thin layer of clumping of HRBC on the bottom of the well considered as positive and the result were recorded. 
vii. The PHA titre was the highest dilution of test sera were complete haemagglutination occur due to the reaction of specific antibody and antigen sensitized tanned HRBC.

The reciprocal of the end point of highest dilution of test sera and sensitized tanned HRBC was considered as titre of the serum. Agglutination was indicated by a flat deposition of a diffuse thin layer of clumping of RBC on the bottom of the wells. The results were recorded after deposition of a diffuse thin layer of clumping of RBC on the bottom of the well, which indicated HA positive, and a compact buttoning with clear zone indicated HA negative. The reciprocal of the highest dilution of sensitized tanned HRBC was considered as titre of the serum.

\subsection{PHA antibody titre}

\section{Results}

The prevaccination mean PHA antibody titre with standard error $( \pm)$ was $\leq 4.0 \pm 0.00$ in chickens of all groups. After three (3) weeks or $21 \mathrm{DPV} t$ he mean PHA antibody titres were $104.00 \pm 11.71$ and $112.00 \pm 10.47$ in groups of birds inoculated with S. gallinarum and S. pullorum respectively. At prebooster

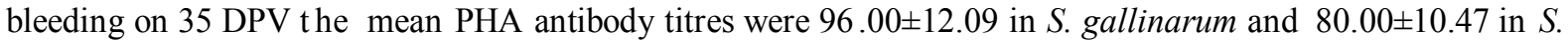
pullorum. After two weeks of booster vaccination, the mean PHA antibody titres were $144.00 \pm 16.00$ and $136.00 \pm 24.00$ in birds vaccinated with S. gallinarum and S. pullorum respectivly. Before challenge, provided at 4 weeks of booster vaccination, the mean PHA antibody titres were $104.00 \pm 11.71$ in both the groups of birds administered with S. gallinarum and S. pullorum. The mean \pm SE PHA titre of vaccinated birds and control birds are presented in Table 1.

Table 1: Mean PHA titre with standard error of sera of chickens vaccinated with Salmonella bivalent vaccine prepared at BAU.

\begin{tabular}{|c|l|c|c|c|}
\hline $\begin{array}{c}\text { Weeks of } \\
\text { vaccination }\end{array}$ & Used antigen & $\begin{array}{c}\text { Pre- vaccinated PHA titre of all } \\
\text { vaccinated and control birds } \\
(\text { Mean } \pm \text { SE) }\end{array}$ & $\begin{array}{c}\text { Post Vaccination PHA titre of } \\
\text { vaccinated group } \\
\text { (Mean } \pm \text { SE) }\end{array}$ & P value \\
\hline 10 & S. gallinarum & $<4 \pm 0.00$ & $104.00 \pm 11.71$ & $112.00 \pm 10.47$ \\
\hline 10 & S. pullorum & $<4 \pm 0.00$ & $96.00 \pm 12.09$ & \multirow{2}{*}{0.0001} \\
\hline 12 & S. gallinarum & $<4 \pm 0.00$ & $80.00 \pm 10.47$ & $144.00 \pm 16.00$ \\
\hline 12 & S. pullorum & $<4 \pm 0.00$ & $136.00 \pm 18.88$ & $104.00 \pm 11.71$ \\
\hline 14 & S. gallinarum & $<4 \pm 0.00$ & $104.00 \pm 11.71$ & \\
\hline 14 & S. pullorum & $<4 \pm 0.00$ & & \\
\hline 16 & S. gallinarum & $<4 \pm 0.00$ & & \\
\hline
\end{tabular}

Legends: $\mathrm{PHA}=$ Passive haemagglutination

Mean $=$ Geomatric mean of 10 birds, $\mathrm{SE}=$ Standard error

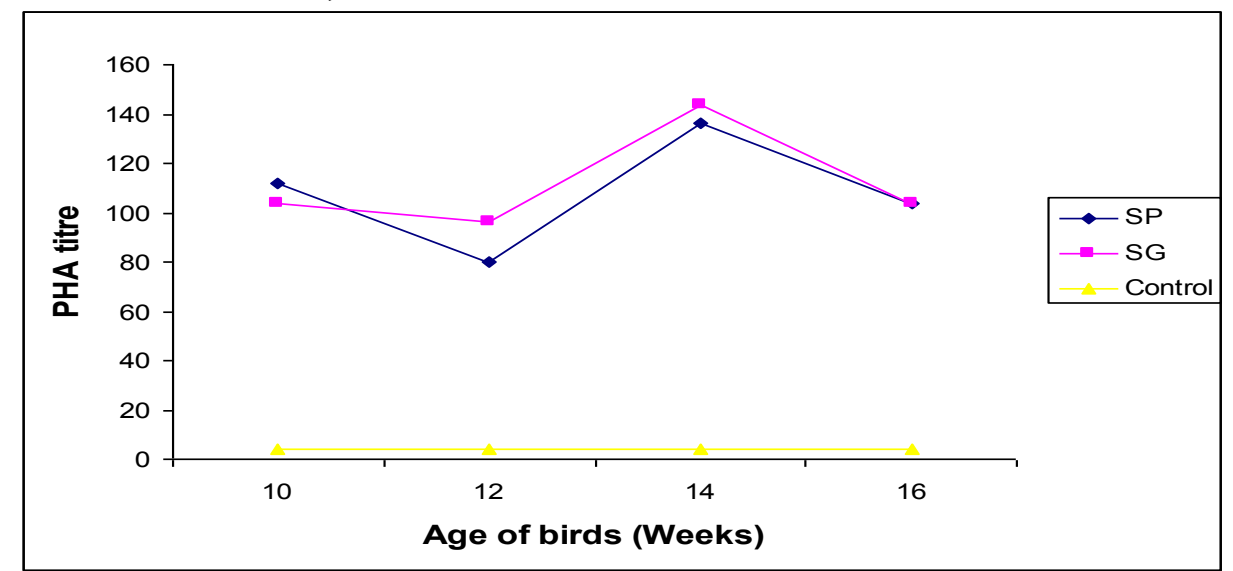

Fig-2: Graphical representation of mean PHA titres with standard error of sera of chickens vaccinated with Salmonella bivalent vaccine prepared at BAU.

\subsection{Results of challenge infection}

Challenge infection at the dose rate of $1 \mathrm{ml}$ (S. pullorum: $8.9 \times 10^{13} \mathrm{CFU} / \mathrm{ml}$ and S. gallinarum: $8.6 \mathrm{x}$ $10^{13} \mathrm{CFU} / \mathrm{ml}$ ) was given separately to the chickens of group both A, B. All birds of the group A were resistant to virulent challenge exposure. All birds of the group B showed sign and symptoms of infection within one day of challenge. It was demonstrated that experimentally prepared Salmonella bivalent vaccine conferred $100 \%$ 
protection against challenge infection given after 4 weeks of secondary (booster) vaccination when unvaccinated control birds were found to be affected with challenge organisms.

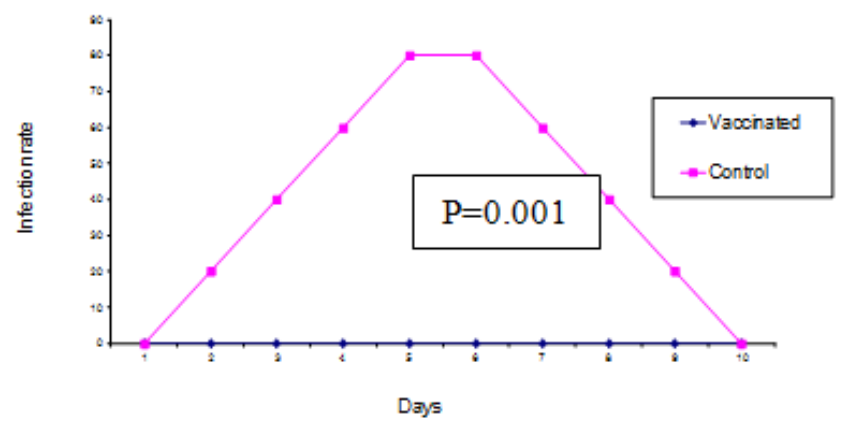

Fig: 3 Graphical representation of post challenge infection

\section{Discussion}

In Bangladesh a good number of commercial companies import Salmonella vaccine for marketing. Such imported vaccines are used without any field trial which should have been mandatory in terms of testing of efficacy. In consideration of this, the efficacy of Salmonella bivalent vaccine produced at LPVRPC, BAU, Mymensingh, was selected for the determination of the serum antibody titre by PHA test. As an essential part of efficacy test, the $\mathrm{LD}_{50}$ of virulent Salmonella gallinarum and Salmonella pullorum was also determined individually so that protection test might be carried out without any question whatsoever. The purity (sterility) and safety test of the concerned vaccine was carried out as per instruction of OIE (2008).

PHA test of sera from vaccinated and control birds were conducted for determination of antibody titre as per the method described by authors mentioned earlier. The pre-vaccinated PHA titre of sera samples of all vaccinated chickens were recorded as $\leq 4 \pm 00$ which was closely related to the findings of Ferdous (2008), Yeasmin (2010) and Jannatun (2010).

Sera collected on 21 and 35 DPV and those collected at two weeks following secondary (booster) vaccination were subjected to PHA test. The test conducted with both Salmonella gallinarum and Salmonella pullorum antigen revealed titre of $104.00 \pm 11.71$ and $112.00 \pm 10.47$ on 21 DPV and $96.00 \pm 12.09$ and $80.00 \pm 10.47$ on $35 \mathrm{DPV}$ and $144.00 \pm 16.00$ and $136.00 \pm 24.00$ at two weeks and $104.00 \pm 11.71$ at four weeks of booster vaccination.

$\mathrm{LD}_{50}$ of $S$. gallinarum and S. pullorum was found to be containing $8.6 \times 10^{13} \mathrm{CFU} / \mathrm{ml}$ and $8.9 \times 10^{13}$ $\mathrm{CFU} / \mathrm{ml}$.The experimental birds, both vaccinated and control, were exposed to protection test (challenge test) after four weeks of booster vaccination. These results were in agreement with the statement of Rahman et.al (2005), who found that the antibody titre reached peak at 4 weeks vaccination in chickens.

Based on the results of the study; it may be calculated that

$i$. The experimental birds having vaccinated with the schedule of primary and secondary (booster) vaccine and exhibiting mean PHA titre of $104.00 \pm 11.71$ and $104.00 \pm 11.71$ at four weeks of booster vaccination were protected following challenge infections with virulent cultures of $S$. gallinarum and $S$. pullorum with a dose of $1 \mathrm{ml}\left(8.6 \times 10^{13} \mathrm{CFU} / \mathrm{ml}\right.$ and $\left.8.9 \times 10^{13} \mathrm{CFU} / \mathrm{ml}\right)$ administered via IM.

ii. $\quad$ Salmonella bivalent vaccine containing S. gallinarum and S. pullorum prepared at LPVRPC fulfilled the criteria of safety, purity, and efficacy and appeared to be dependable for inducing satisfactory level of immunity.

\section{References}

[1]. Begum F, 1992. Studies on the immune response in chickens with experimentally prepared Salmonella gallinarum vaccine. M. S. thesis. Department of Microbiology and Hygiene, Bangladesh Agricultural University, Mymensingh.

[2]. Carter G. R, 1979. Diagnostic Procedures in Veterinary Bacteriology and Mycoplasma. $3^{\text {rd }}$ edition. Charles C. Thomas publisher, USA, 398-417.

[3]. Chowdhury, K. A., Amin, M. M., Rahman, A. and Ali. M. R. 1985. Investigation of natural outbreaks of fowl typhoid. Bangladesh Veterinary Journal, 19: 49-56.

[4]. Ferdous, J. 2008. Immunogenicity study of DLS prepared Salmonella gallinarum vaccine in comparison to commercially available one in layer chicken. M.S. Thesis submitted to the Department of Microbiology and Hygiene, Faculty of Veterinary Sciences, Bangladesh Agricultural University, Mymensingh. pp.38- 39.

[5]. Freeman, B. A. (1985). Burrows text book of microbiology. $22^{\text {nd }}$ edn. W. B. Saunders company, Philadelphia, London, Toronto, Mexici city, Rio de Janeiro, Sydney, Tokyo, pp. 464- 472

[6]. Gast, R. K. (1997). Salmonella infection in Disease of poultry by B.W Calnek, H. John Barnes, Charles W. Beard, Larry R. McDougald, Y. M. Saif, $10^{\text {th }}$ edition, Iowa State University Press, Iowa, USA, pp. 81-93.

[7]. Gifford, D. H.; Shane, S. M.; Hugh, J. M. and Weigler, B. J. 1987. Evaluation of biosecurity in broiler breeder. Avian Disease. 31: 339-344. 
[8]. Haque, M. M., Biswas, H. R. and Rahman, L. 1997. Isolation, identification and production of Salmonella pullorum colored antigen in Bangladesh for the rapid whole blood test. Asian Journal of Animal Sciences. 10: 141-146.

[9]. Jannatun, 2010.Preparation of Fowl Typhoid vaccine from field isolates and determination of efficacy. MS thesis, submitted to the Department of Microbiology and Hygiene, BAU, Mymensingh.

[10]. Kaura, Y. K; Jagjit, S.R.; Kulshrestha, K.; Minakshi, R. C. and Chaturvedi, G. C. (1990). Salmonella gallinarum var. duisburg: An emerging biotype heavy mortality in birds in northern India. Ind. J. Ani. Sci. 60(2): 127-130.

[11]. Kleven, S. H. and Yoder, H. W. (1998). Mycoplasmosis. In: H.G. Purchase, L, H, Arp, C. H. Domermuth and J. E. Pearson (Eds). A Laboratory Manual for the Isolation and Identification of Avian Pathogens, $4^{\text {th }}$ edn. American Association of Avian Pathologists, Kenett Square. PP. 74-78.

[12]. Kumer, A. and Kaushi, R. K. (1988). Investigation of fowl typhoid in Haryana State. Ind. J. Poult. Sci. 23: 104-106.

[13]. Office International Des Epizootics (OIE), 2008. www. oie. Int/ eng/ norms/ MANUAL/ 2008/ pdf/ chapter 2. 3.11. Fowl Typhoid and Pullorum diseases

[14]. Rahman, M. M.; Chowdhury, T. I. M. F.; and Hossain, W. I. M. A. (1979). Surveillance of Salmonella and Escherichia organisms in poultry feed. Bangladesh Veterinary Journal. 15(12): 59-62.

[15]. Rahman, M. M. Khan, Z. U. M. and Rashid, S. M. H. 2005. Evaluation of the efficacy of a bacterin against Salmonella gallinarum infection. Journal of Animal and Veterinary Advances. 4(3): 332-334.

[16]. Sarker, A. J. 1976. The prevalence of avian disease in Bangladesh Agricultural University Poultry Farm. Bangladesh Veterinary Journal. 10(1-4): 672-678.

[17]. Siddique, A. B., Rahman, M. B., Amin, M. M. and Rahman, M. M. 1997. Antibody titres in chicks following pigeon poxvirus inoculation. Bangladesh Veterinary journal. 14: 12-14.

[18]. Shivaprasad H. L. (1997). Pullorum Disease and Fowl Typhoid in Disease of poultry by B.W Calnek, H. John Barnes, Charles W. Beard, Larry R. McDougald, Y. M. Saif, $10^{\text {th }}$ edition, Iowa State University Press, Iowa, USA, pp. 82-93.

[19]. Threlfall, E. J. and Frost, J. A. (1990). The identification, typing and fingerprinting of Salmonella: laboratory aspects and epidemiological applications. J. App. Bact. 69:5-19.

[20]. Tripathy, D.N., Hanson, L.E. and Mysers, W.L.1970. Passive haemagglutination test with fowl pox virus. Avian Diseases. 14: 29-38

[21]. Yeasmin 2010. On farm investigation on the efficacy of Salmonella vaccine prepared at BAU. MS thesis, submitted to the Department of Microbiology and Hygiene, BAU, Mymensingh. 